\title{
EXHIBITIONS AND NOTICES.
}

\section{May 11, 1915.}

\section{Dr. A. Sмiтh Woodward, F.R.S., Vice-President, in the Chair.}

The Secrerary read the following report on the Additions to the Society's Menagerie during the month of April 1915:-

The number of registered additions to the Society's Menagerie during the month of April was 230. Of these 150 were acquired by presentation, 25 by purchase, 38 were received on deposit, 6 in exchange, and 11 were born in the Gardens.

The number of departures during the same period, by death and removals, was 115 .

Amongst the additions special attention may be directed to :-

1 Goeldi's Marmoset (Callimico goeldii), from Bunda River, Bolivia, new to the Collection, deposited on April 14th.

1 Houbara Bustard (Houbara undulata), from North Africa, received on deposit on April 27th.

A valuable Collection of Waterfowl containing sixty-eight individuals representing twenty-five species, presented by Alexander L. Duncan, F.Z.S., on April 23rd.

\section{The House-Fly Exhibition.}

Prof. H. Maxwell Lefroy, M.A., F.Z.S., Curator of Insects, exhibited specimens of various kinds of fly-traps and made the following remarks upon the House-Fly Exhibition:-

"A small exhibition of Flies and methods of dealing with them will be open on Wednesday, May 12th, and continue open while it is of use and interest. There will not necessarily be anything original in the exhibition, and it was planned at first simply to show the American fly-traps, which are not used in this country and which are likely to be valuable. From this it has grown to include all the information about flies that a healthofficer might require, and we are endeavouring to arrange it so that such an officer can obtain in a short time the technical information about flies that is available, without himself having to hunt up the literature. We have also tried to make it useful by getting samples and prices of the necessary chemicals etc., by having copies of books and other literature, and by condensing into a short illustrated pamphlet authoritative information.

Since this was planned the Press have taken it up, somewhat to our embarrassment, and we have had to make it as interesting: and instructive as we can for the general public: so we are enlarging the scope, providing tabloid information and posters, and generally trying to rub in the essential facts.

Flies are likely to be important this year for several reasons the first is that with a shortage of labour scavenging will not be 
so well done, manure cannot be so quickly disposed of, and there will be local outbreaks of flies if the weather conditions are suitable.

The usual vigilance exercised in inspection, and in destroying material capable of breeding flies will be impossible this year; there will be accumulations of manure and refuse in towns, on farms, on market gardens and where cavalry are quartered, and this will provide breeding-material particularly for house-flies.

The second reason is that in areas affected by the war, flies are increasing, because sanitation and the disposal of fly-breeding material will not be possible, and this will accumulate to an unusual extent. I have evidence of this already from the Continent: these flies will not come over here, but they will lead to a greater spread there of the diseases that they carry and we shall be affected; if cholera breaks out in Serbia, Austria, or other parts of South Europe, it may spread in fly-invested areas and get widely diffused. I do not want to be an alarmist, but I think we must be prepared for such possibilities when a war of this magnitude is in progress.

If flies are going to be unusually numerous so will the diseases they carry, and one of these is typhoid: we inoculate the men who go to the front, but we here are not inoculated.

The third consideration is that there is a likelihood of a very terrible plague of flies actually where the fighting is in progress, which will very deeply impress those who are there : no one quite knows where the fighting-line will be, but wherever it is the flies are likely to be a feature. This is a good time, then, to do what we can to rub the facts in, to get them known, to arouse interest, and to help those whose business it will be to fight flies : already we have been visited by Army Doctors anxious to get quickly all the facts about flies, and this will become increasingly useful.

For these reasons we have made all we can of this little exhibition, and, though it is not nearly complete, it contains useful information and will be open at once.

It is not necessary for me to go into the details of the lifehistory and habits of flies to-night: you can see it all in the exhibition to-morrow, and you are probably all aware of the main facts. We are showing the various stages of the House-fly and the Blow-fly, the common flies of houses, where they breed, what they feed on, the diseases they carry, how they carry them, and so on. The facts are condensed on diagrams, posters, pictures, and the methods of fighting flies are described in a short pamphlet.

What can one do against flies? There are three lines on which one can work, adjusting one's methods to local circumstances of course :-

1. Removal or treatment of breeding-material.

2. Traps.

3. Poisons.

The materials in which house-flies lay eggs and develop are 
well known ; they are horse-manure, excrement, rotting vegetablematter such as vegetables, compost heaps, rubbish heaps, and the like: manure, excrement, garbage, and fermenting rubbish are the danger sources for house-flies. For blow-flies animal-matter is the chief source, even in extremely small amounts : a dead mouse, a hollow bone, a putrifying whelk, a dead sparrow, a scrap of meat, a fish-head, these will all nourish blow-fly maggots: you will be astonished when you see what a small amount is needed and what a number of blow-flies will develop from the scraps in the dust-bin.

The number of flies this year will depend very largely on the extent to which this material is removed or destroyed, not only by the authorities but by the efforts of every one concerned. Until people at large realize what a danger flies are and what it is that they breed in, we are certain to have quantities of flies; it is an unpleasant subject that people prefer to leave alone, but there may be enough flies this year to make people want to know about them.

If the breeding-material cannot be disposed of, can it be treated so that it will not breed flies? Can we treat manure without impairing its value, and can we show how to treat the manure-heap in every garden? We have the available information collected, and the original papers can be consulted; so far as is possible inquirers will be advised.

The second method is to trap, and I show to-night two American traps, with Mr. Seth-Smith's improvement, a folding-trap made in the Gardens, and two other patterns of folding-trap that are being tested. These and any improved ones will be shown, and if any are available the prices etc. stated. Some patterns are for home manufacture, some will, we hope, be available at popular prices.

We show also a trap that is meant for the household dust-bin, which will catch any flies going to the dust-bin and any that have developed in it and that seek to escape. If a dust-bin of this kind is used to contain stable-manure it will probably be a very valuable trap for house-flies generally, and the stable become a means of generally reducing flies in the neighbourhood instead of adding to them.

The third method is to poison flies, and this has yielded remarkable results abroad. There are harmless liquids for use indoors and poisons for use by skilled persons outside, particularly for hospitals and large institutions. These will be of greater interest to professional men than to the public generally: we have the original accounts of these, and it will be possible for a health officer to read quickly what has been done.

It may perhaps sound to you as if we knew all about flies, and as if we should be able to solve all the difficulties that will be brought to us-I wish, indeed, it were so. It is astonishing how little practical information there is ; what there is, is largely from America-very little has been done here, and we are very far indeed from having the information we need. 
We have here to-night representatives of the Press, the educators of the man in the street, and the exponents of his collective opinion. I hope Fellows of the Society will forgive me if I take the opportunity to urge the Press to emphasise to the Great British Public this fact, that we are actually at a loss to know how to meet the fly problem here and at the front because the necessary scientific investigation has not been done. As a nation we neglect and underrate the value of applied science; it is not the function of the Zoological Society to deal with the application of Science to national health, and it is the wide sympathies of its Council and officers that enables me to make use of its resources to deal with this problem: but there is no organised body, no department of Government that stimulates and develops the study of Applied Biology. If there had been, we could answer the questions that come in to us daily from municipal health authorities, Army Sanitary officials, and the public, as to means of dealing with flies and other vermin.

I am not talking in a general way, but I have definite specific problems that are in need of solution at once.

1. Baits for Flies. - The recommended baits for fly-traps are formalin, beer, vinegar, milk, alcohol, and a few others : these are things arrived at by chance. It seems likely that we might find a really good bait, something that would draw in every fly for a quarter of a mile round, if we worked systematically on the line of testing substances likely to be found in the breeding-materials that flies seek. What brings the fly to the manure heap? Smell possibly; if so, can we find a substance of not too intolerable a smell that could be used to bait a trap in a corner of the garden and that would really bring in all the flies. I think we can, but it will require investigation, and it is a bad time to start investigating when the problem is imminent: we have actually begun with the assistance of the Organic Chemistry Department of the Imperial College, and we hope to get something out, but it is work that should have been all done long ago.

2. Beside baits based on the fly's breeding-place, can we get a bait based on his food? Why do flies sometimes take formic aldehyde? Is this the best or the only one, or are there other definite substances of far greater attractiveness to flies which they associate with their food? It is worth trying, and obviously if we can get a really potent attractor it will help immensely.

3. Baits based on Sex.-How does the male find the female? By scent, by sight, by what?

I remember in India a planter sent me some fruit-flies with the remark that when he put a particular mosquito essence on his handkerchief these flies followed him continually; the essence contained citronella oil, and a drop of this oil will bring the males of these flies from all around: investigation showed that the female produces this oil, and it is by its scent that the males find them: we have now a method of dealing with this fly.

I quote this quite true story as an example; and it might be 
worth while studying the house-fly and the blow-fly from this point of view.

4. Questions are coming in about treatment of manure-heaps to keep flies away: is there anything deterrent to flies? It happens that we have some recent research work on this very point, but only as regards blow-flies; it is work done at the Cooper Research Laboratory at Watford. There is here an important line of work and one which is going to be of immediate importance.

5. Treatment of Manure-heaps to kill Maggots in them.- Some work has been done on this point in the United States and Canada, but I believe that much better methods only need to be worked out, possibly using the new vapour-poisons that have been found during the last year. In America they recommend borax, but it seems likely that better and cheaper methods will be found.

I have now shown you investigations which, if done in the past, would have enabled us to deal with this fly problem ; so it is, of course, with all branches of science, but I have been able here to give you definite concrete cases and not simply glittering: generalities.

I have devoted more time to this point perhaps than I ought because this particular problem will affect people closely, because the lives of children will continue to be lost till we grapple with it, and because it is not often one gets a chance of reaching the Press. Perhaps some wealthy and enlightened person will endow fly-research, perhaps some organised body will take it up, perhaps even some day the Government will think of it. I do hope that in this case the Press will put the issues clearly and definitely.

To return to the flies. We hope to open the exhibition tomorrow, and to admit the public at certain hours, the health officials, doctors and technical folk at others. We owe much to those who have helped to organise, and who have prepared or lent models, posters, pictures, traps, samples, and appliances. Dr. C. J. Martin, the Director of the Lister Institute, has very kindly revised the pamphlet as regards diseases carried by flies, and we hope to have that out this week.

In these times we all do what we can, and I am privileged to be able to utilise the facilities of the Gardens for this exhibition. It is perhaps a new departure for the Society, an unusual feature that may be looked on as unseemly by some of the Fellows. I think that the circumstances justify it, and that if it does good and anything comes of our work, the Nation will be indebted to the Society, and this incursion into practical applied entomology will not be regretted." 


\section{$2 \mathrm{BHL}$ Biodiversity Heritage Library}

Woodward, Arthur Smith. 1915. "May 11, 1915." Proceedings of the Zoological Society of London 1915, 529-533.

https://doi.org/10.1111/j.1469-7998.1915.tb07610.x.

View This Item Online: $\underline{\text { https://www.biodiversitylibrary.org/item/98466 }}$

DOI: https://doi.org/10.1111/j.1469-7998.1915.tb07610.x

Permalink: https://www.biodiversitylibrary.org/partpdf/72183

\section{Holding Institution}

Smithsonian Libraries

\section{Sponsored by}

Biodiversity Heritage Library

\section{Copyright \& Reuse}

Copyright Status: Public domain. The BHL considers that this work is no longer under copyright protection.

This document was created from content at the Biodiversity Heritage Library, the world's largest open access digital library for biodiversity literature and archives. Visit BHL at https://www.biodiversitylibrary.org. 